\title{
Monitoring adverse events of low-dose glucocorticoid therapy: EULAR recommendations for clinical trials and daily practice
}

\author{
M C van der Goes, ${ }^{1} \mathrm{~J}$ W G Jacobs, ${ }^{1}$ M Boers, ${ }^{2} \mathrm{~T}$ Andrews, ${ }^{3}$ M A M Blom-Bakkers, ${ }^{1}$ \\ F Buttgereit, ${ }^{4}$ N Caeyers, ${ }^{5}$ M Cutolo, ${ }^{6}$ J A P Da Silva, ${ }^{7}$ L Guillevin, ${ }^{8}$ J R Kirwan, ${ }^{3}$ \\ J Rovensky, ${ }^{9} \mathrm{G}$ Severijns, ${ }^{10}$ S Webber, ${ }^{3}$ R Westhovens, ${ }^{10} \mathrm{~J} \mathrm{~W} \mathrm{~J} \mathrm{Bijlsma}{ }^{1}$
}

'Department of Rheumatology and Clinical Immunology, University Medical Center Utrecht, Utrecht, The

Netherlands

2Department of Clinical

Epidemiology and Biostatistics, VU University Medical Centre,

Amsterdam, The Netherlands

${ }^{3}$ University of Bristol Academic

Rheumatology Unit, Bristol

Royal Infirmary, Bristol, UK

${ }^{4}$ Department of Rheumatology

and Clinical Immunology,

Charité Universitätsmedizin

Berlin, Berlin, Germany

${ }^{5}$ EULAR Social Leagues

Patients' Representative, Belgium

${ }^{6}$ Research Laboratory and Academic Unit of Clinical

Rheumatology, Department of Internal Medicine, University of Genova, Viale Benedetto, Italy

${ }^{7}$ Reumatologia, Hospitais da

Universidade de Coimbra,

Portugal

${ }^{8}$ Service de médecine interne, centre de référence national, Plan Maladies Rares, vascularites et sclérodermie, hôpital Cochin, Université Paris-V,

France

${ }^{9}$ National Institute of Rheumatic Diseases Piest'any, Slovakia

${ }^{10}$ Department of Rheumatology, University Hospitals KU Leuven, Belgium

\section{Correspondence to}

Marlies $C$ van der Goes,

Department of Rheumatology

and Clinical Immunology

(F02.127), University Medical

Center Utrecht, P 0 Box

85500, Utrecht $3508 \mathrm{GA}$, The

Netherlands;

m.c.vandergoes@umcutrecht. $\mathrm{nl}$

Accepted 9 March 2010

\section{ABSTRACT}

Objective To develop recommendations on monitoring for adverse events (AEs) of low-dose glucocorticoid (GC) therapy ( $\leq 7.5 \mathrm{mg}$ prednisone or equivalent daily) in clinical trials and daily practice.

Methods Literature was searched for articles containing information on incidence and monitoring of GC-related AEs using PubMed, EMBASE and Cochrane databases. Second, the authors searched for broad accepted guidelines on the monitoring of certain AEs (eg, WHO guidelines on screening for diabetes). Available data were summarised and discussed among experts (rheumatologists and patients) of the EULAR Task Force to decide which potential AEs should be monitored, how and at which interval.

Results Data on monitoring proved to be scarce; most articles were focused on therapeutic effects of GCs, not on occurrence and monitoring of AEs. Most recommendations had to be based on consensus. Those for clinical trials aimed at getting insights into incidence, prevalence and clinical relevance of $\mathrm{AEs}$ to create a comprehensive and valid AE-profile of GC therapy. The set of $A E s$ to monitor is therefore more extensive, and often consists of assessments at baseline and at end of trials. Recommendations for daily practice are meant to protect patients from real dangers, which can be prevented or treated. Standard care monitoring needs NOT be extended for patients on low-dose GC therapy, except for osteoporosis (follow national guidelines), and baseline assessments of ankle edema, fasting blood glucose and risk factors for glaucoma.

Conclusion Given the incompleteness of literature data, consensus-based recommendations on monitoring for GC-related AEs were created, separately for daily practice and clinical trials.

Since their discovery, glucocorticoids (GCs) are being widely used in different diseases. ${ }^{1} 2$ Their effects are mediated by genomic and non-genomic mechanisms. ${ }^{3}$ GCs are beneficial in many inflammatory and rheumatic diseases, because of their anti-inflammatory and immunosuppressive actions, reducing disease activity and pain. In the long term, GCs exhibit disease-modifying capacities in rheumatoid arthritis (RA), such as protective effects on joint destruction. ${ }^{4}$ However, their use is restrained by the occurrence of adverse events (AEs). ${ }^{5-10}$

Despite the established use, there is no definite consensus on the relevant AE-profile of this medication. A common misconception is that AEs

\section{Box 1 Recommendations}

Three general recommendations on monitoring in clinical trials

1. Report all monitoring results of trials

2. Report both on the group level (eg, means) and on the individual patient level (eg, numbers)

3. Develop new tools for assessing specific adverse events

of high-dose GC therapy (>30 $\mathrm{mg}$ prednisone or equivalent daily) occur in low-dose therapy ( $\leq 7.5 \mathrm{mg}$ prednisone or equivalent daily) to the same extent. In the past years this Task Force put effort in standardizing nomenclature ${ }^{11}$ and producing an overview of AEs associated with low-dose GC therapy in RA. ${ }^{12}$ Furthermore, recommendations on the management of systemic GC therapy in rheumatic diseases were formulated. ${ }^{13}$ Recently, an exercise to explore the perspectives of patients and rheumatologists on GCs showed that recommendations on the monitoring of GC-related AEs were desired, but lacking. ${ }^{14}$ Since many of the GC-related AEs are - at least in part - preventable or treatable, the identification of an $\mathrm{AE}$ can be important in daily practice. Currently, great efforts are being made to develop innovative GCs or GC receptor ligands that have an improved therapeutic effect/AE ratio. ${ }^{15} 16$ So for obtaining a true AE-profile of (conventional) GCs and for comparing AEs of innovative GCs with those of conventional GCs, clear guidance and consensus on the monitoring of AEs are desirable.

The aim of this study was to develop recommendations for the monitoring of GC-related AEs of low-dose GC treatment in rheumatic diseases (1) in clinical trials for obtaining high-quality data on the occurrence of AEs and (2) in daily practice for treating patients safely. These recommendations should state which AEs to monitor, how to monitor them and in what frequency.

\section{METHODS}

\section{Literature search}

A review of the published evidence on GC-related AEs in rheumatic diseases was performed using the bibliographic databases PubMed, EMBASE and Cochrane Library in order to provide data for group discussions and make the recommendations as 
evidence-based as possible. The search was focused on prospective studies in rheumatic diseases reporting AEs of GC therapy. Synonyms and plurals of the search terms were used and MESH terms were added for the PubMed search (all search terms are listed in Online Appendix 1). Studies were included if (1) they were prospective, (2) focused on inflammatory rheumatic diseases, (3) GCs were used in dosages up to $10 \mathrm{mg}$ prednisone or equivalent daily and (4) AEs were reported. Although the focus of these recommendations is on low-dose therapy, studies up to $10 \mathrm{mg}$ prednisone or equivalent were included to enlarge the dataset. Many studies reported AEs for GC dosages up to $10 \mathrm{mg}$ daily and we considered the difference between 7.5 and $10 \mathrm{mg}$ daily not to result in misinterpretations. Exclusion criteria were non-European languages, animal studies and case reports.

\section{Data extraction}

After applying inclusion and exclusion criteria and reading fulltext articles, characteristics of relevant studies were recorded. Important items were the study population (number of patients, disease) and GC therapy (preparation, dose and duration). Information about the reporting of AEs was collected, such as the definition of AEs, the method of monitoring, the frequency of monitoring and blinding of investigator. The reported data on occurrence of each AE were recorded.

\section{Summarizing and critically appraising the available data}

The results of the literature search were separated for outcomes of randomised controlled trials (RCTs) and outcomes of prospective cohort studies. If available, information from RCTs was preferred over that from cohort studies, since randomization prevents from possible confounding by indication and data can be compared with a control group without GC treatment. If no RCTs were available for a certain AE, information from cohort studies was used. Regarding the quality of reporting AEs, main problems in interpreting data were described for each AE.

\section{Decisions on monitoring}

The available data were presented to the Task Force consisting of rheumatologists and rheumatic patients and possible monitoring methods were discussed until consensus was reached on the need for monitoring, the method and frequency. For all AEs considered to be candidate for monitoring, it was checked whether broad accepted guidelines (WHO, American Heart Association etc.) on monitoring or screening in the general population were available. For as far as possible, the methods in these broad accepted guidelines were incorporated in this project. The final decision on monitoring was based on evidence on occurrence of each AE, feasibility of its monitoring and importance as valued by participating rheumatic patients and rheumatologists.

\section{RESULTS}

\section{Literature search}

The literature search resulted in 6226, 3654 and 15 hits in PubMed, EMBASE and Cochrane Library, respectively (figure 1). After filtering doubles and screening all titles and abstracts with respect to selection criteria, 348 articles were deemed potentially relevant. After reading the full text, 31 articles were included. Relevant data on occurrence of AEs were extracted from RCTs. ${ }^{17-32}$ There were no data from low-dose studies for six AEs. An additional search for literature on medium to highdose therapy resulted in 14 articles reporting about occurrence of psychosis, osteonecrosis or myopathy. ${ }^{33-46}$

For each AE the available data are summarised in table 1 (an extensive overview is shown in Online Appendix 2). This table also mentions the difficulties in interpreting the available data.

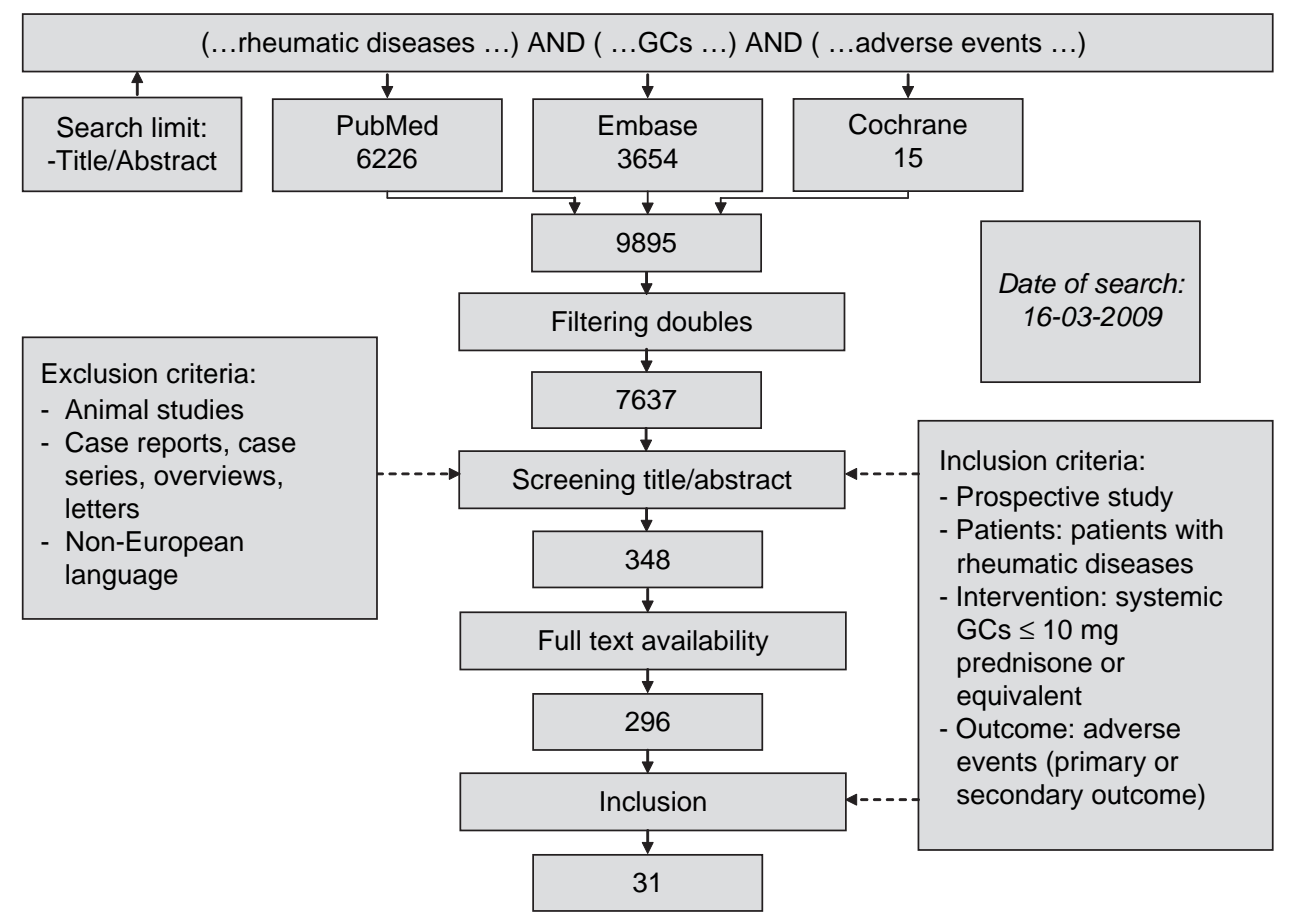

Figure 1 Flow chart of search strategy. The literature search was performed with the databases PubMed, EMBASE and Cochrane Library. After filtering doubles, screening all titles and abstracts with respect to selection criteria and reading the full text versions, 31 articles were included. Relevant data were recorded from these articles. 
Table 1 Monitoring recommendations

\begin{tabular}{|c|c|c|c|c|c|c|}
\hline \multirow[b]{2}{*}{ Adverse event } & \multirow{2}{*}{$\begin{array}{l}\text { Increased risk } \\
\text { in RCTs } \\
\begin{array}{l}\text { N/A, data not } \\
\text { available }\end{array}\end{array}$} & \multirow{2}{*}{$\begin{array}{l}\text { Difficulties in } \\
\text { interpreting results } \\
\text { from RCTs }\end{array}$} & \multirow{2}{*}{$\begin{array}{l}\text { Increased risk in } \\
\text { prospective cohort } \\
\text { studies }\end{array}$} & \multirow{2}{*}{$\begin{array}{l}\text { Status and relevance of AE } \\
\text { c (LE), clinical endpoint } \\
\text { (life expectancy); c ( } 0 \mathrm{oL} \text { ), } \\
\text { clinical endpoint (quality } \\
\text { of life); s, surrogate endpoint; } \\
\text { b, biomarker }\end{array}$} & \multirow[t]{2}{*}{$\begin{array}{l}\text { Feasible method } \\
\text { for monitoring } \\
\text { purpose available }\end{array}$} & \multirow{2}{*}{$\begin{array}{l}\text { Monitoring advised } \\
\text {-, not indicated; } \\
\text { c, in clinical trials; } \\
\text { d, in daily practice }\end{array}$} \\
\hline & & & & & & \\
\hline \multicolumn{7}{|l|}{ Cardiovascular } \\
\hline Dyslipidemia & No & $\mathrm{e}$ & - & $\mathrm{s}$ & Yes & $\mathrm{C}$ \\
\hline $\begin{array}{l}\text { Electrolyte } \\
\text { disturbances }\end{array}$ & $\mathrm{N} / \mathrm{A}$ & - & No & $\mathrm{b}$ & Yes & $\mathrm{C}$ \\
\hline Edema & No & se & - & $c(0 \circ L)$ & Yes & $c d$ \\
\hline $\begin{array}{l}\text { Renal dysfunction } \\
\text { (creatinine } \\
\text { clearance) }\end{array}$ & $\mathrm{N} / \mathrm{A}$ & - & $\mathrm{N} / \mathrm{A}$ & $\mathrm{b}$ & Yes & - \\
\hline Heart failure & No & se & - & $c(\mathrm{LE}, \mathrm{OoL})$ & No & - \\
\hline Hypertension & No & e & - & s & Yes & $\begin{array}{l}\text { c d (standard } \\
\text { care) }\end{array}$ \\
\hline $\begin{array}{l}\text { Ischemic CVD / } \\
\text { atherosclerosis }\end{array}$ & No & $\mathrm{s}$ & - & $c(L E, 0 o L)$ & No & $\begin{array}{l}\text { c d (standard } \\
\text { care) }\end{array}$ \\
\hline \multicolumn{7}{|l|}{ Infectious } \\
\hline Infections & Possibly & $\mathrm{ce}$ & - & $c(\mathrm{LE}, \mathrm{OoL})$ & No & c \\
\hline \multicolumn{7}{|l|}{ Gastro-intestinal } \\
\hline Peptic ulcer disease & Possibly & $\mathrm{cs}$ & - & $c\left(\mathrm{LE}_{1}, \mathrm{OoL}\right)$ & Yes & $\begin{array}{l}\text { c d (standard } \\
\text { care) }\end{array}$ \\
\hline Pancreatitis & $\mathrm{N} / \mathrm{A}$ & - & $\mathrm{N} / \mathrm{A}$ & $c$ (LE) & Yes & - \\
\hline \multicolumn{7}{|l|}{ Psychological } \\
\hline Mood disturbances & Possibly & c se & - & $c(\mathrm{QoL})$ & No & $\mathrm{C}$ \\
\hline Psychosis & N/A & - & Yes* & $c(0 \circ L)$ & No & $\mathrm{C}$ \\
\hline \multicolumn{7}{|l|}{ Endocrine \& metabolic } \\
\hline $\begin{array}{l}\text { Diabetes / glucose } \\
\text { intolerance }\end{array}$ & Possibly & $\mathrm{ce}$ & - & s & Yes & $c d$ \\
\hline $\begin{array}{l}\text { Body weight and fat } \\
\text { redistribution }\end{array}$ & Possibly & c & - & $c(0 \circ L)$ & Yes & $\begin{array}{l}\text { c d (standard } \\
\text { care) }\end{array}$ \\
\hline $\begin{array}{l}\text { Interference with } \\
\text { hormone secretion }\end{array}$ & Yes & se & - & $\mathrm{b}$ & No & $\mathrm{C}$ \\
\hline \multicolumn{7}{|l|}{ Dermatological } \\
\hline Skin atrophy & N/A & - & N/A & $c(0 \circ L)$ & No & $\mathrm{c}$ \\
\hline $\begin{array}{l}\text { Acne, hirsutism, } \\
\text { alopecia, bruisability }\end{array}$ & No & se & - & $c(0 \circ L)$ & Yes & c \\
\hline \multicolumn{7}{|l|}{ Musculo skeletal } \\
\hline Osteoporosis (BMD) & Possibly & $\mathrm{ce}$ & - & $\mathrm{s}$ & Yes & $c d$ \\
\hline Osteonecrosis & N/A & - & Yes $^{*}$ & $c(\mathrm{OoL})$ & No & $\mathrm{c}$ \\
\hline Myopathy & $\mathrm{N} / \mathrm{A}$ & - & Yes $^{*}$ & $c(0 \circ L)$ & No & C \\
\hline \multicolumn{7}{|l|}{ Ophthalmological } \\
\hline Cataract & No & se & - & $c(0 \circ L)$ & Yes & $\mathrm{C}$ \\
\hline $\begin{array}{l}\text { Glaucoma (intra-ocular } \\
\text { pressure) }\end{array}$ & Yes & se & - & $\mathrm{s}$ & Yes & $c d$ \\
\hline
\end{tabular}

*Data indicating that risk may be increased with high-dose glucocorticoid therapy.

The 'increased risk' columns describe the risk of occurrence for all adverse events (AEs). Preferably, data from randomised controlled trials (RCTs) were used. If lacking, data from prospective cohort studies were included. Difficulties in interpreting results from RCTs are mentioned. 'Endpoint inaccurately defined' means there are problems with the definition of an AE (eg, What is 'diabetes'? Cut off values?). In case of 'small numbers' only a few studies (or: limited number of patients included) report an AE and therefore drawing firm conclusions is impossible. 'Conflicting data' mean that different studies show opposite outcomes on occurrence of an AE. The relevance of AEs is split in three different levels. A biomarker is a characteristic that is objectively measured and evaluated as an indicator of normal biologic processes, pathogenic processes or pharmacologic responses to a therapeutic intervention. A surrogate endpoint is a biomarker intended to substitute for a clinical endpoint, that is, a biomarker that is expected to predict presence or lack of clinical benefit or harm. A clinical endpoint is a characteristic or variable that reflects how a patient feels or functions ( $0 \mathrm{oL}$, quality of life), or how long a patient survives (LE, life expectancy).

$\mathrm{AE}$, adverse event; $\mathrm{BMD}$, bone mineral density; CVD, cardiovascular disease; RCT, randomised clinical trial.

In general, no definite conclusions can be drawn on the occurrence of most AEs, because there often is a lack of good quality evidence. Most studies had been designed to assess treatment effects, not to assess AEs. Specific problems in interpreting data were addressed. Inadequately defined AEs (eg, what values or parameters for diagnosing diabetes were used?) made it difficult to compare results. In case of small numbers (only a few studies, or limited number of patients included) drawing firm conclusions was impossible. Moreover, often conflicting data were present, meaning that different studies showed opposite outcomes on occurrence of an AE.

\section{Decisions on monitoring}

The available evidence was discussed within the Task Force and appropriate monitoring methods were considered. It was decided to develop separate sets of recommendations for clinical trials and daily practice, because of different aims of monitoring in these two situations. For daily practice, monitoring is meant to protect patients from real dangers, which can be prevented or treated. The burden of monitoring should be low and reliable interpretation of the monitoring test needs to be possible. Therefore monitoring was advised for clinically important and not very rare AEs. Monitoring in clinical trials also serves the purpose of gaining 
scientific insight into incidence, prevalence and clinical relevance of AEs to create a true AE-profile of GC therapy. Therefore the set of AEs to monitor in clinical trials is more comprehensive.

For some AEs, circadian rhythms play an important role. Monitoring of parameters, such as blood pressure and blood glucose, should preferably be performed at the same time of day (eg, in the morning in fasting state) to optimise the value of the measurements and to allow good comparisons between different assessments and patients.

The decision-making on monitoring is described for a couple of AEs in more detail below. The final recommendations for monitoring are summarised in table 2 . Comprehensive data are enclosed in Online Appendix 2.

\section{Monitoring in daily practice and clinical trials: diabetes as an example}

Outcomes of RCTs reporting on the development of diabetes and the increase of blood glucose levels during GC therapy are conflicting. Developing diabetes after starting low-dose GC treatment seems rare. Progression of already impaired glucose tolerance to overt diabetes is possible. In daily practice, there should be awareness for these possible problems and monitoring should be performed at start of therapy and during follow-up according to standard patient care.

The WHO guidelines state that diabetes can be diagnosed with fasting blood glucose values or oral glucose tolerance tests. ${ }^{47}$ Screening with urinary glucose values is not sensitive and thus not recommended. Therefore we recommend obtaining fasting blood glucose and insulin levels at least at start and end of clinical trials. With these parameters and the Homeostasis Model Assessment (HOMA) the steady state $\beta$-cell function and insulin sensitivity can be estimated. ${ }^{48}$ In case of overt diabetes before treatment, patients should be instructed to carefully monitor their blood glucose level after starting GC therapy.

\section{Monitoring in clinical trials only: hypertension and skin atrophy as an example}

Hypertension: Literature did not show an increased risk for hypertension in patients on low-dose GC treatment. Screening for hypertension is part of standard patient care in daily practice. There is no indication for extra blood pressure monitoring because of GC treatment. In clinical trials, measuring blood pressure is part of good clinical practice. We recommend to measure blood pressure at least at start and end of trials and to report the outcomes in future articles. Reporting should not only be on group level (mean values for treatment groups), but also on patients' level (number of patients with hypertension according to an internationally accepted definition ${ }^{49}{ }^{50}$ ). This will give insight into the clinical relevance of a possible blood pressure increase and will indicate if an increase of the mean group value is based on many small blood pressure increases, or on some severe cases of hypertension.

Skin atrophy: Literature did not report on the occurrence of skin atrophy during oral low-dose GC therapy. Despite the absence of literature data, skin atrophy is thought to be a relatively frequently occurring AE, but not easy to record. Since skin atrophy is not preventable or treatable, monitoring in daily practice is not recommended.

However, it would be valuable to create information about the occurrence of this AE. Patients can be asked for the presence of skin atrophy at start and end of trials. This will give subjective results. In studies with topical GCs, sonography has been used to study (epi)dermal thickness and total skin thickness objectively, for example at the volar aspect of the arm. ${ }^{51}{ }^{52} \mathrm{We}$ strongly support the idea of measuring the skin thickness in at least one trial (with a study duration of at least 1 year) to get good insight into the occurrence of skin atrophy with low-dose oral GC therapy.

\section{DISCUSSION}

It is remarkable that after 60 years of GC use in clinical practice, there is no certainty about the actual incidence of AEs. Therefore, the EULAR Task Force on GCs set out to formulate recommendations for the monitoring of GC-related AEs, based on reports of GC-related AEs in literature.

\section{From studying literature on GC-related AEs to three general recommendations}

All GC literature has possible problems with confounding. First, confounding by indication can be assumed present in all observational literature on GCs, including cohort studies. Only the process of randomization prevents this problem and therefore data from randomised studies were preferred data from over non-randomised studies in this project. The underlying disease can also influence the reporting of AEs. For example, psychological symptoms are linked to GC therapy, but also to disease such as systemic lupus erythematosus (SLE). ${ }^{53} 54$ Likewise osteoporosis is linked to GCs, but also to active disease in RA and SLE. Third, comorbidity can be an important factor. Longer RA duration is accompanied by more comorbidity, and more comorbidity could lead to polypharmacy. ${ }^{55}$ Toxicity of other medication could be attributed to GCs. Interactions between medication can increase the occurrence of AEs, such as the combination of GCs and NSAIDs, which may lead to gastric ulcers.

The extensive literature search revealed dose-dependent relations between GC use and occurrence of certain AEs and showed at the same time that for many AEs good quality evidence on occurrence during low-dose therapy is lacking. ${ }^{79}$ To enlarge the available dataset, although the project was focused on monitoring of low-dose GC therapy, studies with GCs up to $10 \mathrm{mg}$ prednisone or equivalent were included. However, the studies included were mostly not designed and powered to assess AEs but were primarily focused on treatment effects after 1 or 2 years of treatment, so the reporting on the occurrence of AEs was often limited. Nevertheless, assuming most of the published clinical trials have been performed according to good clinical practice dictating broad safety measures, probably more safety checks have been performed than those reported in the publications. Therefore, our first general recommendation is to report all monitoring results of trials (see box 1).

Furthermore, often reporting turned out be on the mean group level (glucose levels, weight, blood pressure), which gives no insight into the prevalence of the AEs and only limited insight into clinical relevance, because the actual number of patients with an $\mathrm{AE}$ is not known. So our second general recommendation is to report AEs also on the number of patients level (see box 1).

Finally, some AEs are difficult to assess. Regarding psychological and behavioural AEs and appearance or signs of Cushing's syndrome, new tools should be developed to assess them (third general recommendation) (see box 1).

\section{RECOMMENDATIONS ON MONITORING}

Separate recommendations were formulated for daily practice and clinical trials. Although the occurrence of AEs is dependent 
Table 2 Recommendations on monitoring including method and interval

\begin{tabular}{|c|c|c|c|c|}
\hline \multirow[b]{2}{*}{ Adverse event } & \multicolumn{2}{|c|}{ Assessments and feasible methods of monitoring } & \multicolumn{2}{|l|}{ Minimal monitoring frequency } \\
\hline & Clinical trials & $\begin{array}{l}\text { Daily practice (if different } \\
\text { from clinical trials) }\end{array}$ & Clinical trials & Daily practice \\
\hline \multicolumn{5}{|l|}{ Cardiovascular } \\
\hline Dyslipidemia & Blood: fasting lipids & - & Start, end & - \\
\hline Electrolyte disturbances & Blood: sodium and potassium & - & Start, end & - \\
\hline Edema & Physical examination: ankle edema & - & Start, end & Start \\
\hline Hypertension & Blood pressure measurement & - & Start, end & Standard care \\
\hline Ischemic CVD & $\begin{array}{l}\text { 1. Questioning } \\
\text { 2. Carotid intima-media thickness* }\end{array}$ & Questioning & $\begin{array}{l}\text { 1. Start, end } \\
\text { 2. Start, end }\end{array}$ & Standard care \\
\hline \multicolumn{5}{|l|}{ Infectious } \\
\hline Infections & $\begin{array}{l}\text { Questioning: occurrence, treatment } \\
\text { with antibiotics }\end{array}$ & - & Start, during follow-up & - \\
\hline \multicolumn{5}{|l|}{ Gastro-intestinal } \\
\hline Peptic ulcer disease & $\begin{array}{l}\text { 1. Questioning: complaints } \\
\text { 2. Blood: haemoglobin }\end{array}$ & - & $\begin{array}{l}\text { 1. Start, end } \\
\text { 2. Start, end }\end{array}$ & Standard care \\
\hline \multicolumn{5}{|l|}{ Psychological } \\
\hline Mood disturbances & Questioning & - & Start, end & - \\
\hline Psychosis & $\begin{array}{l}\text { Active monitoring not indicated; } \\
\text { report of occurrence }\end{array}$ & - & - & - \\
\hline \multicolumn{5}{|l|}{ Endocrine and metabolic } \\
\hline Diabetes/glucose intolerance & $\begin{array}{l}\text { Blood: fasting glucose and insulin } \\
\text { (HOMA) }\end{array}$ & Blood: fasting glucose & Start, end & Start, standard care \\
\hline $\begin{array}{l}\text { Body weight and fat } \\
\text { redistribution }\end{array}$ & $\begin{array}{l}\text { 1. Height } \\
\text { 2. Weight } \\
\text { 3. Abdominal circumference }\end{array}$ & $\begin{array}{l}\text { 1. Height } \\
\text { 2. Weight }\end{array}$ & $\begin{array}{l}\text { 1. Start, end } \\
\text { 2. Start, during follow-up } \\
\text { 3. Start, end }\end{array}$ & Standard care \\
\hline $\begin{array}{l}\text { Interference with hormone } \\
\text { secretion }\end{array}$ & $\begin{array}{l}\text { 1. Questioning: menstrual } \\
\text { disturbances/loss of libido } \\
\text { 2. Blood: ACTH stimulation test* }\end{array}$ & - & $\begin{array}{l}\text { 1. Start, end } \\
\text { 2. Start, within } 48 \mathrm{~h} \text { after stopping }\end{array}$ & - \\
\hline \multicolumn{5}{|l|}{ Dermatological } \\
\hline Skin atrophy & $\begin{array}{l}\text { 1. Questioning } \\
\text { 2. Sonography for skin thickness } \\
\text { (volar part of arm) })^{*}\end{array}$ & - & $\begin{array}{l}\text { 1. Start, end } \\
\text { 2. Start, end }{ }^{* *}\end{array}$ & - \\
\hline $\begin{array}{l}\text { Acne, hirsutism, alopecia, } \\
\text { bruisability }\end{array}$ & Questioning & - & Start, end & - \\
\hline Hirsutism & Questioning & - & Start, end & - \\
\hline \multicolumn{5}{|l|}{ Musculo skeletal } \\
\hline Osteoporosis (BMD) & $\begin{array}{l}\text { 1. DEXA } \\
\text { 2. X-rays dorsal spine (if possible) } \\
\text { 3. Questioning for fractures }\end{array}$ & - & $\begin{array}{l}\text { 1. Start, end }{ }^{* *} \text { (for newly started } \\
\text { GCs: also at six months) } \\
\text { 2. Start, end } \\
\text { 3. Start, end }\end{array}$ & $\begin{array}{l}\text { Standard care } \\
\text { according to local } \\
\text { guidelines }\end{array}$ \\
\hline Osteonecrosis & $\begin{array}{l}\text { Active monitoring not indicated; } \\
\text { imaging only in case of complaints }\end{array}$ & - & - & - \\
\hline Myopathy & Questioning & - & Start, end & - \\
\hline \multicolumn{5}{|l|}{ Ophthalmological } \\
\hline Cataract & Ophthalmologic evaluation & - & Start, end ${ }^{* *}$ & - \\
\hline Glaucoma (intra-ocular pressure) & $\begin{array}{l}\text { Ophthalmologic evaluation with } \\
\text { tonometry }\end{array}$ & $\begin{array}{l}\text { Questioning for risk factors: } \\
\text { family history, high myopia, } \\
\text { diabetes }\end{array}$ & Start, end ${ }^{* *}$ & $\begin{array}{l}\text { Start (ophthalmologic } \\
\text { evaluation in case of risk } \\
\text { factors) }\end{array}$ \\
\hline
\end{tabular}

*This is the preferable monitoring method, but probably less feasible. We ask to incorporate at least one of these items in future trials.

** Monitoring is only indicated for studies with a duration of at least 1 year.

For all adverse events (AEs) feasible monitoring methods are described and preferable monitoring intervals are given. These are minimum recommendations, indicating that they can be intensified for patients with additional risk factors for a certain AE. In most cases monitoring is recommended at start and at the end of trials. In case of drop-out, the 'end'-monitoring should be performed at time of drop-out. Broad explanation about these recommendations is enclosed in Online Appendix 2 . In Online Appendix 3 suggestions for questioning are given. ACTH, adrenocorticotropic hormone; BMD, bone mineral density; CVD, cardiovascular disease; GCs, glucocorticoids; HOMA, homeostasis model assessment.

on the dose and duration of GC therapy and the underlying disease, phase of treatment and co-morbidity also play a role. So the recommendations for daily practice do not replace the "normal' screening on the presence of frequently occurring disorders in an older-growing population (such as diabetes and hypercholesterolemia), usually performed by the general practitioner. Measurements which should already be part of good clinical care in all rheumatic patients were tagged as 'standard care' in table 2.

Apart from safety, monitoring in clinical trials also serves the purpose of gaining scientific insight into the incidence, prevalence and clinical relevance of AEs to create a true AE-profile of GC therapy. In future clinical trials with GCs there should be extra interest and awareness in not only performing this monitoring, but also in reporting the results. The results should be reported in a standardised way, even if no problem or increased occurrence of an AE has been found. This would enable future meta-analyses on GC-related AEs. In clinical trials, for most AEs monitoring is recommended at least at baseline and end, for maximal feasibility and because data on the time to develop an AE are lacking. These are meant as 'minimum recommendations': specific aspects of individual patients may warrant a higher frequency of monitoring and/or a more comprehensive set of items to monitor. With relatively few efforts, a large body of data on occurrence of GC-related AEs can be created. In case of drop-out, we would advise to perform the 'end-measurements' immediately. 
This exercise has shown that evidence on occurrence is scarce for several AEs, such as ischemic cardiovascular disease, adrenal insufficiency and skin atrophy. We want to emphasise the need for more evidence on these three AEs in particular and want to stimulate identifying at least one of these three items in future clinical trials on GCs with a duration of at least 1 year. Measuring intima-media thickness for the development of atherosclerosis, performing ACTH stimulation tests after stopping GC therapy for the occurrence of adrenal failure and applying sonography for the development of skin atrophy will help to reveal the occurrence and severity of these AEs.

\section{CONCLUSION}

Given the incompleteness of literature data, consensus-based recommendations on monitoring of GC-related AEs were created, separately for daily practice and clinical trials. For daily practice, the Task Force recommends that standard care monitoring need NOT be expanded for patients on low-dose GC therapy, with a few exceptions. For clinical trials, the recommendations are more extensive in order to create a comprehensive and valid AE-profile of GC therapy.

Funding The activities of this Task Force are financially supported by EULAR.

Competing interests None.

Provenance and peer review Not commissioned; externally peer reviewed.

\section{REFERENCES}

1. Hench PS, Kendall EC, Slocumb $\mathrm{CH}$, et al. Effects of cortisone acetate and pituitary ACTH on rheumatoid arthritis, rheumatic fever and certain other conditions. Arch Intern Med (Chic) 1950;85:545-666.

2. Hillier SG. Diamonds are forever: the cortisone legacy. J Endocrinol 2007;195:1-6.

3. Stahn C, Löwenberg M, Hommes DW, et al. Molecular mechanisms of glucocorticoid action and selective glucocorticoid receptor agonists. Mol Cell Endocrinol 2007:275:71-8

4. Kirwan JR, Bijlsma JW, Boers M, et al. Effects of glucocorticoids on radiological progression in rheumatoid arthritis. Cochrane Database Syst Rev 2007;CD006356.

5. Caldwell JR, Furst DE. The efficacy and safety of low-dose corticosteroids for rheumatoid arthritis. Semin Arthritis Rheum 1991;21:1-11.

6. Saag KG, Koehnke R, Caldwell JR, et al. Low dose long-term corticosteroid therapy in rheumatoid arthritis: an analysis of serious adverse events. Am J Med 1994;96:115-23.

7. Curtis JR, Westfall AO, Allison J, et al. Population-based assessment of adverse events associated with long-term glucocorticoid use. Arthritis Rheum 2006;55:420-6

8. McDonough AK, Curtis JR, Saag KG. The epidemiology of glucocorticoid-associated adverse events. Curr Opin Rheumatol 2008;20:131-7.

9. Huscher D, Thiele K, Gromnica-Ihle E, et al. Dose-related patterns of glucocorticoidinduced side effects. Ann Rheum Dis 2009;68:1119-24.

10. Hoes JN, Jacobs JW, Verstappen SM, et al. Adverse events of low- to mediumdose oral glucocorticoids in inflammatory diseases: a meta-analysis. Ann Rheum Dis 2009;68:1833-8.

11. Buttgereit F, da Silva JA, Boers M, et al. Standardised nomenclature for glucocorticoid dosages and glucocorticoid treatment regimens: current questions and tentative answers in rheumatology. Ann Rheum Dis 2002:61:718-22.

12. Da Silva JA, Jacobs JW, Kirwan JR, et al. Safety of low dose glucocorticoid treatment in rheumatoid arthritis: published evidence and prospective trial data. Ann Rheum Dis 2006;65:285-93.

13. Hoes JN, Jacobs JW, Boers M, et al. EULAR evidence-based recommendations on the management of systemic glucocorticoid therapy in rheumatic diseases. Ann Rheum Dis 2007;66:1560-7.

14. Van der Goes MC, Jacobs JW, Boers M, et al. Patients' and rheumatologists perspectives on glucocorticoids an exercise to improve the implementation of the EULAR recommendations on the management of systemic glucocorticoid therapy in rheumatic diseases. Ann Rheum Dis 2009 Epub ahead of print.

15. Song IH, Gold R, Straub RH, et al. New glucocorticoids on the horizon: repress, don't activate! J Rheumatol 2005;32:1199-207.

16. Schäcke H, Schottelius A, Döcke WD, et al. Dissociation of transactivation from transrepression by a selective glucocorticoid receptor agonist leads to separation of therapeutic effects from side effects. Proc Natl Acad Sci USA 2004;101:227-32

17. Capell HA, Madhok R, Hunter JA, et al. Lack of radiological and clinical benefit over two years of low dose prednisolone for rheumatoid arthritis: results of a randomised controlled trial. Ann Rheum Dis 2004;63:797-803.
18. Boers M, Nurmohamed MT, Doelman CJ, et al. Influence of glucocorticoids and disease activity on total and high density lipoprotein cholesterol in patients with rheumatoid arthritis. Ann Rheum Dis 2003:62:842-5.

19. Loftus J, Allen R, Hesp R, et al. Randomized, double-blind trial of deflazacort versus prednisone in juvenile chronic (or rheumatoid) arthritis: a relatively bone-sparing effect of deflazacort. Pediatrics 1991;88:428-36.

20. van Everdingen AA, Jacobs JW, Siewertsz Van Reesema DR, et al. Low-dose prednisone therapy for patients with early active rheumatoid arthritis: clinical efficacy, disease-modifying properties, and side effects: a randomized, double-blind, placebocontrolled clinical trial. Ann Intern Med 2002;136:1-12.

21. Kirwan JR, Hällgren $\mathrm{R}$, Mielants $\mathrm{H}$, et al. A randomised placebo controlled 12 week trial of budesonide and prednisolone in rheumatoid arthritis. Ann Rheum Dis 2004;63:688-95.

22. Wassenberg $\mathbf{S}$, Rau R, Steinfeld $\mathrm{P}$, et al. Very low-dose prednisolone in early rheumatoid arthritis retards radiographic progression over two years: a multicenter, double-blind, placebo-controlled trial. Arthritis Rheum 2005;52:3371-80.

23. Kirwan JR. The effect of glucocorticoids on joint destruction in rheumatoid arthritis. The Arthritis and Rheumatism Council Low-Dose Glucocorticoid Study Group. N Engl Med 1995;333:142-6.

24. Boers $\mathbf{M}$, Verhoeven AC, Markusse HM, et al. Randomised comparison of combined step-down prednisolone, methotrexate and sulphasalazine with sulphasalazine alone in early rheumatoid arthritis. Lancet 1997;350:309-18.

25. Svensson B, Boonen A, Albertsson K, et al. Low-dose prednisolone in addition to the initial disease-modifying antirheumatic drug in patients with early active rheumatoid arthritis reduces joint destruction and increases the remission rate: a two-year randomized trial. Arthritis Rheum 2005;52:3360-70.

26. Sheldon $\mathbf{P}$. Ileum-targeted steroid therapy in rheumatoid arthritis: doubleblind, placebo-controlled trial of controlled-release budesonide. Rheumatol Int 2003;23:154-8.

27. van Everdingen AA, Siewertsz van Reesema DR, Jacobs JW, et al. The clinical effect of glucocorticoids in patients with rheumatoid arthritis may be masked by decreased use of additional therapies. Arthritis Rheum 2004:51:233-8.

28. Kirwan JR, Hickey SH, Hällgren R, et al. The effect of therapeutic glucocorticoids on the adrenal response in a randomized controlled trial in patients with rheumatoid arthritis. Arthritis Rheum 2006;54:1415-21.

29. Haugeberg G, Strand A, Kvien TK, et al. Reduced loss of hand bone density with prednisolone in early rheumatoid arthritis: results from a randomized placebocontrolled trial. Arch Intern Med 2005;165:1293-7.

30. van Everdingen AA, Siewertsz van Reesema DR, Jacobs JW, et al. Low-dose glucocorticoids in early rheumatoid arthritis: discordant effects on bone mineral density and fractures? Clin Exp Rheumatol 2003;21:155-60.

31. Hansen $\mathbf{M}$, Podenphant J, Florescu A, et al. A randomised trial of differentiated prednisolone treatment in active rheumatoid arthritis. Clinical benefits and skeletal side effects. Ann Rheum Dis 1999;58:713-8.

32. Laan $\mathbf{R F}$, van Riel PL, van de Putte LB, et al. Low-dose prednisone induces rapid reversible axial bone loss in patients with rheumatoid arthritis. A randomized controlled study. Ann Intern Med 1993;119:963-8.

33. Jover JA, Hernández-García C, Morado IC, et al. Combined treatment of giant-cell arteritis with methotrexate and prednisone. a randomized, double-blind, placebocontrolled trial. Ann Intern Med 2001;134:106-14.

34. Chau SY, Mok CC. Factors predictive of corticosteroid psychosis in patients with systemic lupus erythematosus. Neurology 2003:61:104-7.

35. Caporali R, Cimmino MA, Ferraccioli G, et al.; Systemic Vasculitis Study Group of the Italian Society for Rheumatology. Prednisone plus methotrexate for polymyalgia rheumatica: a randomized, double-blind, placebo-controlled trial. Ann Intern Med 2004;141:493-500.

36. Hunder GG, Sheps SG, Allen GL, et al. Daily and alternate-day corticosteroid regimens in treatment of giant cell arteritis: comparison in a prospective study. Ann Intern Med 1975;82:613-18.

37. Nesher G, Sonnenblick M, Friedlander Y. Analysis of steroid related complications and mortality in temporal arteritis: a 15-year survey of 43 patients. J Rheumatol 1994;21:1283-6.

38. Chevalet $\mathbf{P}$, Barrier $\mathrm{JH}$, Pottier $\mathrm{P}$, et al. A randomized, multicenter, controlled trial using intravenous pulses of methylprednisolone in the initial treatment of simple forms of giant cell arteritis: a one year followup study of 164 patients. J Rheumatol 2000;27:1484-91.

39. Nagasawa K, Tada Y, Koarada S, et al. Very early development of steroid-associated osteonecrosis of femoral head in systemic lupus erythematosus: prospective study by MRI. Lupus 2005:14:385-90.

40. Oinuma K, Harada Y, Nawata Y, et al. Osteonecrosis in patients with systemic lupus erythematosus develops very early after starting high dose corticosteroid treatment. Ann Rheum Dis 2001:60:1145-8.

41. Ono K, Tohjima T, Komazawa T. Risk factors of avascular necrosis of the femoral head in patients with systemic lupus erythematosus under high-dose corticosteroid therapy. Clin Orthop Relat Res 1992;89-97.

42. Zizic TM, Marcoux C, Hungerford DS, et al. Corticosteroid therapy associated with ischemic necrosis of bone in systemic lupus erythematosus. Am J Med 1985:79:596-604. 
43. Aranow C, Zelic of S, Leslie D, et al. Clinically occult avascular necrosis of the hip in systemic lupus erythematosus. J Rheumatol 1997;24:2318-22.

44. Hollingworth P, de Vere Tyndall A, Ansell BM, et al. Intensive immunosuppression versus prednisolone in the treatment of connective tissue diseases. Ann Rheum Dis 1982:41:557-62.

45. Mazlumzadeh M, Hunder GG, Easley KA, et al. Treatment of giant cell arteritis using induction therapy with high-dose glucocorticoids: a double-blind, placebo-controlled, randomized prospective clinical trial. Arthritis Rheum 2006:54:3310-8.

46. Spiera RF, Mitnick HJ, Kupersmith M, et al. A prospective, double-blind, randomized, placebo controlled trial of methotrexate in the treatment of giant cell arteritis (GCA) Clin Exp Rheumatol 2001;19:495-501.

47. Definition and diagnosis of diabetes mellitus and intermediate hyperglycaemia. Report of a World Health Organization/International Diabetes Federation consultation. WHO Press, 2006.

48. Haffner SM, Kennedy E, Gonzalez C, et al. A prospective analysis of the HOMA model. The Mexico City Diabetes Study. Diabetes Care 1996;19:1138-41.

49. Chobanian AV, Bakris GL, Black HR, et al.; National Heart, Lung, and Blood Institute Joint National Committee on Prevention, Detection, Evaluation, and Treatment of High Blood Pressure; National High Blood Pressure Education Program Coordinating Committee. The Seventh Report of the Joint National Committee on Prevention,
Detection, Evaluation, and Treatment of High Blood Pressure: the JNC 7 report. JAMA 2003:289:2560-72

50. Whitworth JA. World Health Organization, International Society of Hypertension Writing Group. 2003 World Health Organization (WHO)/International Society of Hypertension (ISH) statement on management of hypertension. J Hypertens 2003;21:1983-92

51. Cossmann M, Welzel J. Evaluation of the atrophogenic potential of different glucocorticoids using optical coherence tomography, 20-MHz ultrasound and profilometry; a double-blind, placebo-controlled trial. Br J Dermatol 2006;155:700-6.

52. Korting HC, Unholzer A, Schäfer-Korting M, et al. Different skin thinning potential of equipotent medium-strength glucocorticoids. Skin Pharmacol Appl Skin Physiol 2002;15:85-91.

53. Denburg SD, Carbotte RM, Denburg JA. Psychological aspects of systemic lupus erythematosus: cognitive function, mood, and self-report. J Rheumatol 1997;24:998-1003.

54. Kozora E, Thompson LL, West SG, et al. Analysis of cognitive and psychological deficits in systemic lupus erythematosus patients without overt central nervous system disease. Arthritis Rheum 1996;39:2035-45.

55. Treharne GJ, Douglas KM, Iwaszko J, et al. Polypharmacy among people with rheumatoid arthritis: the role of age, disease duration and comorbidity. Musculoskeletal Care 2007;5:175-90. 